\title{
NOTAS
}

\section{GÓNGORA Y UN MITO CLÁSICO}

Hay poetas que descubren nuevos caminos y otros que exploran territorio abierto. Garcilaso descubrió una nueva dirección para la poesía española y después vinieron generaciones de poetas que exploraron sus posibilidades expresivas. Luis de Góngora es uno de los exploradores más importantes de la poesía española. Un aspecto fundamental de su genio consiste, no en haber descubierto nuevos temas, ni en haber usado técnicas originales, sino más bien en su visión personal y su inimitable ingenio, cualidades que llevaron la tradición renacentista a nuevas y controvertibles alturas. Es precisamente este espíritu de exploración lo que hace posible la originalidad más grande de Góngora que es, según el importante libro de A. Collard, su "afirmación de una poesía intimista y personalista"1.

Una de las convenciones que Góngora heredó fue la alusión frecuente a la mitología clásica. La tradición se enriqueció enormemente en sus manos y su genio innovador introdujo también la inversión burlesca del idealismo tradicional. El afán de encontrar siempre nuevos modos de expresarse llevaba, no sólo a lo que para muchos han sido excesos, sino también hacia la parodia ${ }^{2}$. De modo que, uno de los maestros de la lírica petrarquista es al mismo tiempo el autor de dos sardónicos -y brillantes- romances de Hero y Leandro.

Esta "tradicionalidad original" se puede ver de una manera muy clara en Góngora en relación con un mito clásico. El mito de la caída de Icaro atrajo a gran número de poetas del renacimiento, la mayoría italianos y españoles. Vieron en la figura de Ícaro lo totalmente opuesto a lo que habían visto los poetas clásicos, para quienes el hijo de Dédalo había simbolizado el castigo a la temeridad o a la desobedien$\mathrm{cia}^{3}$. Los poetas del renacimiento preferían ver en él un ejemplo de la ambición humana premiada con la inmortalidad, como lo expresó primero Jacopo Sannazaro* ${ }^{4}$ hacia finales del siglo quince; Tansillo, Tasso

1 Andrér Collard, Nueva poesia; conceptismo, culteranismo en la critica española, Madrid y Waltham, Mass., 1967, p. x.

2 Para Borges, "The baroque is that style which deliberately exhausts (or tries to exhaust) its possibilities and borders on its own caricature". Cit. en la introducción a Labyrinths: Selected stories and other writings, ed, by Yates \& Irby, New York, 1964

3 Preparo un libro sobre el tema de Icaro en España que tratará en detalle la tradición clásica. Algo hay sobre el tema en RoBert VIvier, Frères du ciel, quelques aventures poétiques d'Icare et de Phaéthon, Bruselas, 1962.

4 Icaro cadde qui: queste onde il sanno, / che in grembo accolser quella audaci penne; / qui fini il corso, e qui il gran caso arvenne / che darà invidia agli aitri clie 
y otros italianos siguieron a Sannazaro ${ }^{5}$, y la tradición se trasladó a España con Garcilaso, cuyo soneto XII es la primera expresión española de esta admiración por la audacia del joven volador:

Si para refrenar este deseo

loco, imposible, vano, temeroso, y guarecer de un mal tan peligroso, que es darme a entender yo lo que no creo,

no me aprovecha verme cual me veo, o muy aventurado o muy medroso, en tanta confusión, que nunca oso fiar el mal de mi que lo poseo,

¿qué me ha de aprovechar ver la pintura de aquel que con las alas derretidas cayendo, fama y nombre al mar ha dado,

y la del que su fuego y su locura llora entre aquellas plantas conocidas, apenas en el agua resfriado?

Después vinieron Cetina, Aldana, Acuña, Hurtado de Mendoza, Herrera y Cervantes, entre otros españoles y portugueses ${ }^{\top}$.

El mito de ícaro parece haber ejercido una atracción particular en Luis de Góngora. Tal vez haya habido algo en su vida, tan persistentemente marcada por la ambición y el fracaso, que contribuyó a tal fascinación, pero de todos los poetas de la época ninguno ha encontrado la figura de Ícaro tan tentadora y sugestiva. En la obra de Herrera y Villamediana se pueden encontrar referencias bastante frecuentes al mito, pero no la gama de actitudes ni las ingeniosas complejidades de visión y de expresión que inspiró en el poeta de Córdoba. En un mundo poético poblado de imágenes de vuelo y bruscos cambios de fortuna, Icaro ocupa un puesto importante.

Uno de los disfraces con que ícaro aparece en la poesía, tanto clásica como renacentista, es el del artista que quiere abandonarse a su

verranno. / Aventuroso e ben gradito affanno, / poi che, morendo, eterna fama ottenne! / Felice chi in tal fato a morte venne, / c'un si bel pregio ricompensi il danno! / Ben pò di sua ruina esser contento, / se al ciel volando a guisa di colomba, / per troppo ardir fu esanimato e spento; / et or del nome suo tutto rimbomba / un mar si spacioso, uno elemento! / Chi ebbe al mondo mal si larga tomba? (Jacopo Sannazaro, Opere volgari, Bari, 1961, p. 195).

5 Tansillo, Il canzoniere, t. 1 (Napoli, 1926), pp. 4, 5-6 y 164, The Oxford book of Italian verse, 2: ed., Oxford, 1952, p. 202; Fasciuello, apud Michele Ricciardello, "Il mito de Icaro e la correlazione", en RNo, 8 (1967), p. 287; Torouato Tasso, Rime, Bologna, 1900, p. 345; Castellani, Rime diverse, t. 1, Venecia, 1549, p. 51, también publicado por Joseph G. Fucilla, "Etapas en el desarrollo del mito de Icaro en el Renacimiento y en el Siglo de Oro", en "Superbi colli" e altri saggi, Roma, 1963, pp. 45-84; Caro, Rime, Venecia, 1757, p. 95; Guarini, Rime, Venecia, 1598, f. 64v.

6 Garcilaso de la Vega, Obras completas, ed. Elias Rivers, Madrid, 1964, p. 14.

7 G. de Cetina, Obras, ed. Hazañas y la Rúa, Sevilla, 1895, p. 17; Aldana, Poesias, Madrid, 1957, p. 7; Acuña, Varias poesias, Madrid, 1954, p. 361; Hurtado, BAE, t. 32, p. 88; Herrera, Poesias, ed. García de Diego, Madrid, 1962, pp. 16, 55, 90 y 108, y Rimas inéditas, ed. J. M. Blecua, Madrid, 1948, pp. 89 y 114; Cervantes, Obras completas, ed. Schevill y Bonilla, t. 3, Madrid, 1918, p. 14. 
musa pero teme el fracaso si intenta temas muy elevados. En el caso de una mujer que quiere inmortalizar, le asombran su belleza tan brillante e inefable, y en el caso de un personaje noble que honra, su gran valor o entendimiento, de los que su pluma es indigna. Herrera recurre varias veces al mito para expresar esta petitio humilis. En una ocasión, por ejemplo, se dirige a don Alfonso Pérez de Guzmán, duque de Medina:

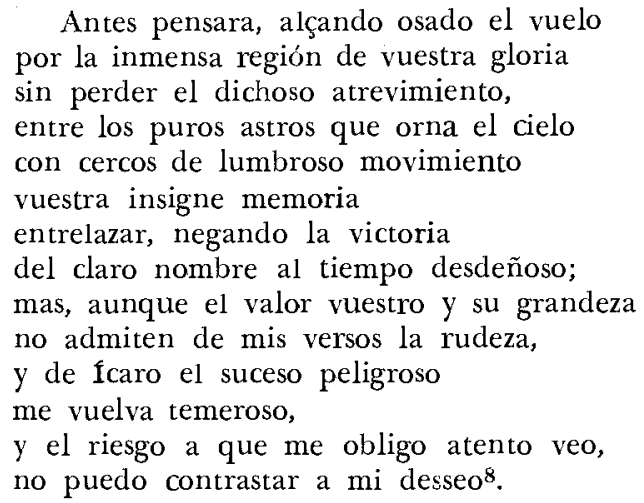

Dentro de la misma tradición se encuentra esta décima de Góngora:

Por más daños que presumas, vuela, Ícaro español, que al templo ofreces del Sol en poca cera tus plumas. Blanco túmulo de espumas haga el Betis a tus huesos; que sus gloriosos excesos, si de mi Musa los fías, los venerarán los días en los álamos impresos.

(MrLLÉ, 152) 0

Góngora evoca el mito con su acostumbrada economía verbal que, en este caso, exige la brevedad de los octosílabos. Con unas pocas alusiones nos recuerda la esencia del cuadro de Ícaro. Los "gloriosos excesos" expresan de una manera muy concisa el sentimiento de muchos poetas de la época al considerar el mito. Al contrario del poeta aludido por Horacio en sus famosos versos:

$8 B A E$, t. 32 , p. 315 .

9 Todas las referencias pertenecen a LUIS DE Góngora, Obras completas, ed. Mulcé, 6a ed., Madrid 1967. En adelante citaré al editor más número del poema, o página en las obras de mayor extensión. Los textos de las Soledades corresponden a la edición de Dámaso Alonso; los sonetos a Sonetos completos, ed. B. Ciplijauskaité, Madrid, 1969; y las letrillas a Letrillas de Luis de Góngora, ed. Robert Jammes, París, 1963. 
Pindarum quisquis studet aemulari,

Iule, ceratis ope Daedalea

nititur pinnis vitreo daturus

noḿina ponto. (Odas IV, 2)

Góngora anima a este joven a pensar, no en los peligros, sino en la inmortalidad que pueden traer los esfuerzos artísticos. Lxpresando una gran confianza, el poeta parece asegurar a su compañero andaluz que tendrá fama si sigue su propia musa.

Ícaro no es la única figura mitológica en la décima. Tal vez sea el río, en que puede caer este joven, lo que sugiere la historia de Faetón que terminó su ardiente carrera en el Po, pero cuando llegamos a los álamos del último verso (las hermanas de Faetón, que lloraban su muerte, fueron convertidas en álamos, según Ovidio, Metamorfosis, II, 345-346) es claro que los dos mitos, asociados antes en Tansillo y Garcilaso, están entrelazados ${ }^{10}$. La mezcla de mitos, no siempre deliberada, fue un rasgo cada vez más frecuente de esta poesía, que encontramos sobre todo en Lope de Vega ${ }^{11}$.

Probablemente el poema más conocido de Góngora dentro de la tradición de Ícaro es este soneto:

No enfrene tu gallardo pensamiento del animoso joven mal logrado el loco fin, de cuyo vuelo osado fue ilustre tumba el húmido elemento.

Las dulces alas tiende al blando viento, $y$ sin que el torpe mar del miedo helado tus plumas moje, toca levantado la encendida región del ardimiento.

Corona en puntas la dorada esfera do el pájaro real su vista afina, y al noble ardor desátese la cera;

que al mar, do tu sepulcro se destina, gran honra le será, y a su ribera, que le hurte su nombre tu rüina.

(Mirlé, 241)

Como el poema anterior, éste es una exhortación a la confianza. La persona a quien se dirige el poeta debe olvidar, como lo había hecho la persona del soneto de Garcilaso, los peligros ejemplificados en la historia de fcaro y pensar en la gloria, aunque sea póstuma. La aventura $-\mathrm{y}$ no está claro si es erótica o artística ${ }^{1 \cdot 2}$ - puede traer el desastre pero trae también la inmortalidad. Como lo había expresado Tansillo, "I'honor fia eterno se mortal è il salto".

10 Para Tansillo cf. supra, nota 5; para Garcilaso, cf. supra, p. 89.

11 Véase Lope DE VeGa, Obras completas, ed. José Manuel Blecua, Barcelona, 1969 , pp. 747 s. y 857.

12 Ciplijauskaité nota que varios epígrafes indican la posibilidad que el poema se dirija a don Luis Gaytán de Ayala, poeta. R. JAmmes (Études sur l'ceuvre poétique de Góngora, Bordeaux, 1967, p. 361) lo trata como un soneto de amor. La relación entre el poeta y el amante es el tema de unas páginas muy interesantes de GabRIEL CeLAYA, Exploración de la poesia, Barcelona, 1964, pp. 15-88. 
Como en muchos otros poemas de la misma tradición, no se menciona el nombre de Ícaro. Con referencias elípticas a detalles bien conocidos, el poeta habla directamente al joven como si éste fuera el mismo Ícaro. En este soneto el uso de la elipsis se lleva a extremos. El mar es "húmido elemento", sinécdoque bastante frecuente en Góngora pero esta vez con un posible precedente de Sannazaro: "un mar si spacioso, uno elemento". Otra expresión elíptica presenta el sol mediante una referencia mitológica: "dorada esfera / do el pájaro real su vista afina", alusión a la creencia antigua de que el águila, ave de Júpiter, puede mirar directamente al sol sin cegarse. Las alusiones, una sobre otra, forman un ingenioso tejido de hilos familiares.

El soneto es rico en hallazgos gongorinos. En el reverso de la fórmula acostumbrada "nombre al mar ha dado", "puso al mar eterno nombre" 13 , Góngora anima a su interlocutor a quitarle al mar su nombre, cambiándolo. Esta novedad es significativa. Las imágenes de competencia, a veces violenta, son frecuentes en la poesía de Góngora. Un ejemplo de ello es el soneto "Mientras por competir..." (MiLlé, 228) donde, a pesar del tema nada violento, casi todas las metáforas son de competencia agresiva - "competir... en vano... menosprecio... triunfa... desdén", etc.

Góngora recuerda también algo que no todos los poetas del Renacimiento parecen saber y es que, según una tradición recogida por Virgilio y otros, Ícaro dio su nombre, no sólo al mar, sino también a una isla cercana (irónicamente, es el nombre de la isla el que ha per. manecido hasta hoy). Otra originalidad de nuestro poeta es que a la imagen consagrada del protagonista suspendido entre su alta meta y el posible desastre, añade una observación que acentúa aún más la agonía de la situación. En el verso 6 , el mar, fuente de peligro, se convierte en el mismo miedo, congelado. El verdadero peligro para el joven es el temor, o la falta de confianza, interpretación que podría tal vez aceptar un psicólogo.

La tradición del amante como víctima de sus propios pensamientos remonta cuando menos a Petrarca - "Volo con l'ali del pensiero al cielo..."14. Sigue en otros poetas, Tansillo, por ejemplo - "l'animoso mio pensiero..." $15_{-}$, y se convierte en una constante de la poesía petrarquista, asociada muchas veces, como en estas endechas de Hurtado de Mendoza, con la figura de Ícaro:

Pensamiento mío,
no me deis tal guerra,
pues sois en la tierra
de quien sólo fío;
que si en tal altura
no vais poco a poco
quedaré por loco

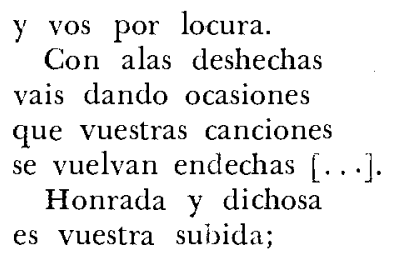

13 Cf. Garcllaso, soncto XII y G. de Cemtina, Obras, ed. cit., p. 17.

$1 \pm$ Canzoniere, ed. G. Contini, Torino, 1964, p. 186.

15 Véase el soneto "Amor m'impenna l'ale...", Canzoniere, t. 1, Napoli, 1926, p. 4. 
pero la caida muy más peligrosa.

¿Qué buen fin espera

quien va $\sin$ recelo subiendo en el cielo con alas de cera?

De vuestros antojos vencido el volar

daréis nombre al mar que ha hecho mis ojos.

$Y$ al luto después traerás la venganza por mí, y la esperanza y yo por los tres...16

Los versos iniciales de la comedia Las firmezas de Isabela demuestran que esta tradición sigue viva en Góngora:

¿De qué seno infernal, oh pensamiento,

o, por dónde has venido,

si de tus alas torpes huye el viento?

(MILlÉ, p. 709)

En la canción "Qué de invidiosos montes..." (MILlé, 388), los pensamientos amorosos se ponen alas para llegar volando al lado de la amada. Al final de la primera estrofa, donde el poeta expresa su tristeza a causa de la distancia que lo separa de su dama, dice "el noble pensamiento / por verte viste plumas, pisa el viento". La expresión parece tan artificiosa que, si no fuera por el tono muy idealista del poema, podría parecer irónica.

En el romance "Minguilla la siempre bella..." (Millé, 84), el amor de Gil por la bella pastora es expresado en claras, si bien veladas, alusiones al mito de Ícaro:

Gil desde sus tiernos años

aras le erigió devoto,

humildemente celando

tanto culto aun de sí propio.

Profanólo alguna vez

pensamiento que, amoroso,

volando en cera atrevida

nadó, en desengaños loco.

La historia de Ícaro, que ocupa 53 versos en Ovidio, es ahora tan familiar que bastan cinco palabras, "volando en cera atrevida / nadó".

En estos versos brilla el genio burlón del pocta cordobés. En el contexto de un amor entre personas con nombres tan rústicos como Gil y Minguilla, y en un romance, no hay lugar para los áltares y ritos del amor cortés. Góngora crea este ambiente convencional para después profanarlo con la intrusión de un pensamiento osado que cae tan ingloriosamente al agua que, lejos de encontrar la muerte y la inmortalidad, se baña. La referencia al mundo de la mitología ovidiana es irónica. La yuxtaposición Gil/Ícaro enfrenta la convención literaria del amor como culto difícil y peligroso, con una situación real como es el amor entre dos pastores, y complica así la estatura de 
İcaro, que era, para los poetas anteriores, símbolo de aspiraciones amorosas más cortesanas.

En la letrilla "Hágasme tantas mercedes..." (MıLlé, 33), el poeta suplica a sus pensamientos que no vuelen demasiado alto y que no salgan de su casa; deben ser humildes y quedarse escondidos:

Hágasme tantas mercedes, temerario pensamiento que no te fíes el viento, ni penetres las paredes.

(MILlÉ, p. 424)

En la primera estrofa el pobre amante amonesta a sus pensamientos peligrosos con el ejemplo de Ícaro:

$$
\begin{aligned}
& \text { Pensamiento, no presumas } \\
& \text { tanto de tu humilde vuelo, } \\
& \text { que el sujeto pisa el cielo, } \\
& \text { y al suelo bajan las plumas: } \\
& \text { otro barrió las espumas } \\
& \text { del Mediterráneo Mar, } \\
& \text { pudiendo mejor volar } \\
& \text { que tú ahora volar puedes. }
\end{aligned}
$$

A veces es la esperanza del amante lo que causa su angustia, como en esta letrilla:

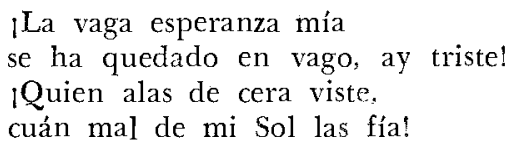

(MilLé, 164)

Como en Herrera, el peligro yace en una dama cuyo nombre poético es Sol. En la estrofa, la historia de Ícaro informa el relato de las esperanzas del amante, ahogadas, como en las endechas citadas de Hurtado, en sus propias lágrimas:

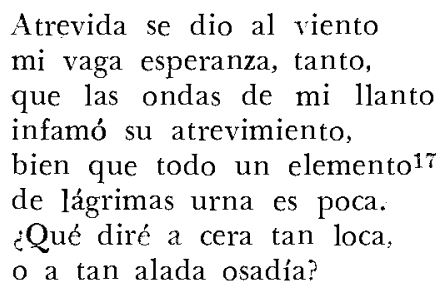

(MILLÉ, p. 361)

17 Cf. supra, p. 91, "húmido elemento" en el soneto "No enfrene...". 
¡Qué maravilla de concisión! Aquí, y en otro caso que veremos, la caída de Ícaro traerá, no la fama de su nombre, sino el descrédito ("infamó...") . A Góngora le encantan estas inversiones de la tradición.

La mariposa tiene un largo abolengo como imagen del destino humano. Desde la antigüedad clásica la belleza y la fragilidad del insecto han sugerido la fugacidad de las atracciones del mundo ${ }^{18}$. La idea de la mariposa fatalmente atraída a la llama tiene evidentes paralelos con el mito de Ícaro. Un soneto de Góngora, que contiene unos versos magníficos, trata el tema de la mariposa pero con indicios de que al mismo tiempo el poeta está consciente del ejemplo de f́caro.

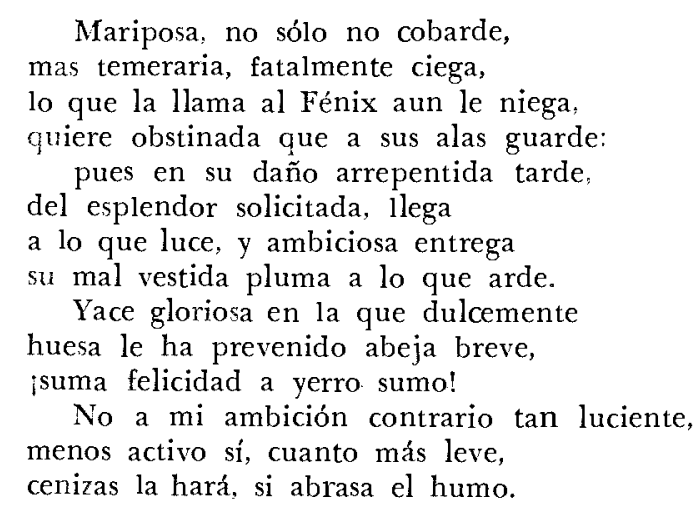

(MıLLÉ, 372)

Soneto difícil con un tema muy frecuente en Góngora y sobre todo asociado con Ícaro. En su admirable edición de los sonetos de nuestro poeta, B. Ciplijauskaité menciona un soneto del divino Herrera, "La incauta y descuidada mariposa..." como parecido a éste de Góngora ${ }^{19}$. El cotejo sirve, no sólo para mostrar la originalidad del cordobés, sino también para reforzar la impresión de la contaminación con la imagen de Ícaro. La expresión "mal vestida pluma" ‘es nada más una expresión gongorina de la fragilidad de las alas del insecto o hay también una reminiscencia del vuelo del hijo de Dédalo?

Hasta aquí, las diferencias sobre el tema de f́caro como símbolo de un dilema existencial son bastante convencionales, aunque no faltan, claro, abundantes muestras del ingenio innovador de Góngora. En la tradición de Garcilaso y Cetina, Ícaro era la imagen del amante o artista -estos papeles a veces se confunden- osado pero desafortunado,

18 Cf. Petrarca: "Come talora al caldo tempo sole / semplicetta farfalla al lume avezza / volar negli occhi per sua vaghezza, / onde aven ch'ella more, altri si dole" (Rime, ed. N. Zingarelli, Bologna, 1963, p. 818) y Dante: "angelica farfalla, / che vola alia giustizia senza schermi" (Purgatorio, X, 121-122). Para un estudio de la imagen de la mariposa en la poesía isabelina, en especial Edmund Spencer, véase Don Camrron Allen, "Muiopotmos, or the fate of the butterflie" en su libro Image and meaning, Baltimore, 1960, pp. 20-41.

19 B. Ciplijauskatré, op. cit., p. 296. El soneto en cuestión se encuentra en Rimas inéditas, p. 59 . 
que se alza en las alas de la inspiración o en las prestadas de Cupido. O bien, siguiendo a Petrarca, fcaro ha simbolizado la audacia de los pensamientos o esperanzas amorosos. Hemos visto también indicios del proceso de desmitificación que sufre el panteón clásico en esta época. Pero en la obra de Góngora, sobre todo en una comedia, encontramos una gama mucho más amplia de contextos en que aparece Icaro, muchos de ellos sorprendentes o irónicos. Uno de los ejemplos más impresionantes de la evocación extravagante del mito es el soneto dedicado al túmulo construido por la ciudad de Écija para conmemorar, en 1611, la muerte de la reina Margarita, mujer de Felipe III:

Ícaro de bayeta, si de pino Cíclope no, tamaño como el rollo. crolar quieres con alas a lo pollo, estando en cuatro pies a lo pollino? ¿Qué Dédalo te induce peregrino a coronar de nubes el meollo, si las ondas que el Betis de su escollo desata, ha de infamar tu desatino?

No des más cera al Sol, que es bobería, funeral avestruz, máquina alada, ni alimentes gacetas en Europa.

Aguarda a la ciudad, que a mediodía, si masse Duelo no en capirotada, la servirá masse Bochorno en sopa.

(MILLÉ, 315)

Este soneto -que está entre lo mejor de la vena satírica de Góngorase complica por la cantidad de alusiones al túmulo, difíciles de interpretar si no se lo ha visto. La mofa inicial, reforzada por la acentuación de la primera sílaba y por la asociación irónica con el nombre mitológico, abre la puerta a un complejo de referencias peyorativas caracterizadas en su mayoría por el contraste entre lo sublime del vuelo icáreo y la pretensión grotesca del monumento. El túmulo es ícaro en su ambición pero queda en la tierra por su tamaño y el peso de los materiales. La cera de las velas que se derrite en el calor de Andalucía, se convierte en la imaginación del poeta en la cera de las alas que hizo Dédalo. El túmulo quiere ser ave (jun pollo!) pero es tan torpe como un animal terrestre (jun pollino!). En lugar de dar fama eterna a las aguas en que cae, este Ícaro otra vez va a traer la deshonra a las aguas, no muy profundas, del Guadalquivir; no logra siquiera despegar de la tierra. El contexto reduce el ejemplo de ícaro al nivel de la burla.

En Las firmezas de Isabela un joven que no quiere casarse es visto como un Ícaro a pesar suyo, "que entre rayos y entre olas, / si no se quema las plumas, / a fe que no se las moja" (Mille, p. 730). Lelio no arde de amor por la dama - no la conoce-- pero de todos modos quiere huir del posible peligro. No necesita amonestaciones sobre el riesgo de dejarse llevar por Cupido. Ya considera el matrimonio "la más estrecha mazmorra / que tiene Argel" y pide permiso a su padre 
para ausentarse. Con esta presentación de un Ícaro como novio mal dispuesto, estamos muy lejos del idealismo asociado con el mito en Tansillo y Garcilaso.

En la misma comedia Góngora nos ofrece nuestra primera mujerÍcaro. Violante, lastimada por el supuesto rechazo de Marcelo y ofendida por la sugerencia del gracioso Tadeo de que ya se ha entregado al hombre que ama, ella se defiende altaneramente:

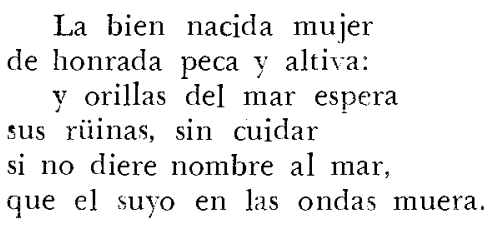

(Millé, p. 767)

Violante, en su orgullo, es Ícaro. En una variación brillante de la tradición, no le importa que su orgullo no le dé inmortalidad. La mujer debe evitar la fama, aun si esto implica la oscuridad.

Tal vez el Ícaro más ingenioso de todos está en la misma comedia. Emilio está enseñando a Galeazo los milagros de Toledo - "ciudad metrópoli de España"- y Galeazo pregunta " $\mathrm{Y}$ aquel quién es, que con osado vuelo / a la casa de el rey le pone escalas?" Emilio contesta:

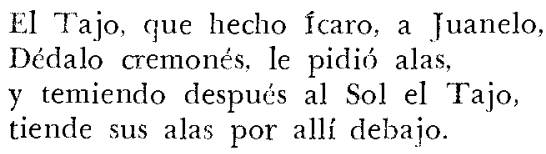

$$
\text { (MILlÉ, p. 776) }
$$

Se refiere irónicamente al esquema malogrado del arquitecto italiano Juanelo Turriano para levantar con esclusas las aguas del Tajo al nivel de la ciudad ${ }^{20}$. Góngora ve el río, en su vana tentativa por alzarse hasta la ciudad, como Ícaro, ambicioso pero destinado al fracaso.

El marco más extenso e intrincado para este mito en Góngora es su obra maestra, las Soledades. El tema del poema, frecuente en la tradición pastoril, es la vanidad de la ambición mundana y todo "moderno artificio" frente a un cuadro líricamente idealizado de los placeres sencillos del hombre en un estado de inocencia. Surgen a menudo imágenes de vuelo que expresan lo transitorio del mundo físico, como el vuelo de la "veloz saeta" en el famoso soneto "Menos solicitó..." Entre éstas los vuelos ambiciosos con alas prestadas tienen un lugar importante. Un crítico $^{21}$ ha advertido la presencia del mito de Ícaro en el poema pero todavía no se ha comentado su importancia fundamental para la temática de la obra. La figura del hijo de Dédalo aparece por todo el

20 Francisco de Quevedo, El Buscón, ed. Américo Castro, nota, p. 95; y el conde de Cedillo. Toledo en el siglo xvi, pp. 93 y 150.

21 L. J. Woodward, "Two images in the Soledades of Góngora", MLN, 76 (1961), $773-785$ 
poema e ilustra, en momentos críticos, el tema desde diferentes perspectivas.

Un joven trata de huir del mundo después de una decepción amorosa; naufraga -símbolo de sus infortunios- y llega casi ahogado a la orilla de un lugar desierto. Después de escalar una peña, una luz lejana lo guía hasta el campamento de unos cabreros, que lo acogen con gran cortesía. Los versos que siguen forman parte de un apóstrofe extático al nuevo mundo que le rodea al cual contrasta con el que acaba de abandonar:

No a la soberbia está aquí la mentira dorándole los pies, en cuanto gira

la esfera de sus plumas,

ni de los rayos baja a las espumas

favor de cera alado.

Oh bienaventurado

albergue a cualquier hora!

(I, 129-135)

Hay aquí dos imágenes de la vanidad de la vida cortesana -el pavo real e Ícaro. En este lugar no hay nadie que lisonjee al pavo real del cortesano diciéndole cuán hermosos son sus pies ${ }^{22}$, y el favor de otros no está sujeto a cambios bruscos de fortuna, como estuvo Ícaro en su huida de Creta. Al principio del poema Ícaro se ve asociado con el tema central.

Un tema semejante tiene el episodio de halconería al final de la segunda Soledad, que contiene una referencia implícita al mito de Ícaro. La culminación de la escena es la muerte de un cuervo que, atraído hacia el oro de los ojos de un búho, se convierte en la pelota de un fatal juego entre dos halcones, pierde sus plumas y cae muerto. El castigo de la avaricia por la pérdida de las plumas de la vanidad, sugiere la presencia escondida del vuelo malogrado del joven Ícaro.

No se condena todo caso de ambición en Soledades. E1 único pasaje donde se nombra a f́caro es la evocación de uno de los competidores en el concurso de salto largo, hacia el final de la primera Soledad.

Bien que impulso noble de gloria, aunque villano, solicita

a un vaquero de aquellos montes, grueso, membrudo, fuerte roble 23 que, ágil a pesar de lo robusto, al aire se arrebata, violentando lo grave tanto, que lo precipita -ícaro montañés- su mismo peso,

22 Salcedo Coronel parafrasea asi: "No está aquí la mentira hermoseando los de. fectos al poderoso, al soberbio", f. 39 r.

23 El texto de Salcedo Coronel dice "membrudo, alado roble", que insiste aún más en la idea del vuelo. 
de la menuda hierba el seno blando piélago duro hecho a su rüina.

$$
\text { (I, 1002-1011) }
$$

Este concurso deportivo es la contraparte del episodio que acabamos de ver, el de la noble caza con halcones, que ocupa una posición análoga en la segunda parte. Los protagonistas aquí son "membrudos", mientras el príncipe cazador era "en miembros no robusto". La palabra "noble", ausente en el contexto anterior, surge aquí con toda naturalidad. Estos juegos son el pasatiempo inocente y saludable de gente sencilla sin trompas ni plumas. El mito de Ícaro, presente en los dos textos, apunta hacia una diferencia clave entre las dos escenas. El Ícaro que deja su elemento natural por "impulso noble / de gloria" caerá -la ley es severa- pero salvo y en tierra firme. Su vuelo no está motivado por la avaricia ni por la vanidad personal y por eso no se precipita al mar. Este volador afirma, no niega, su humanidad.

Así que, en momentos críticos del poema se recurre al mismo mito, en contextos deportivos, con distintas pero complementarias perspectivas sobre la ambición. La ciega ambición del cuervo, asociada con el deporte noble de la caza, contrasta con la ambición inocua del campesino.

En las Soledades encontramos también la imagen de Ícaro más conocida en la poesía anterior, la del amante que se atreve a amar a una dama tan brillante y tan peligrosa como el mismo sol. Esta identificación que es casi un lugar común en la poesía de Herrera, aparece en Góngora solamente una vez, al principio de la segunda parte de su gran poema. El joven recuerda la triste experiencia que lo llevó a peregrinar; habla de su evasión de las cadenas de amor: ha huido, como f́caro, del encarcelamiento:

Audaz mi pensamiento

el cenit escaló, plumas vestido, cuyo vuelo atrevido

-si no ha dado nombre a tus espumas--

de sus vestidas plumas

conservarán el desvanecimiento

los anales diáfanos del viento.

(II, 137-143)

Sus hazañas serán recordadas sólo en el viento, no en un mar ni en una isla. Vaga por el mundo tratando de olvidar su insensatez o "solicitando en vano / las alas sepultar de mi osadía" (II, 149-150).

En textos cuya tradición es más evidente encontramos a veces no sólo la originalidad de un poeta, sino también sus preocupaciones más hondas. El mito de Ícaro parece ser la fuente de varias imágenes clave de Góngora - las plumas, la cera, el viento, el vuelo- y de varios temas que trató a menudo -la ambición, la fama, la brevedad de la vida. En su obra esta figura mitológica se presenta en una gran variedad de escenarios y en un gran número de evocaciones geniales. Trató 
el tema en versos tradicionales con más frecuencia y con menos seriedad que sus precursores. Enriqueció como muy pocos lo hicieron la tradición mitológica europea y, al explorar tan asiduamente sus posibilidades expresivas ad absurdum, contribuyó también al decaimiento de este repertorio de ideales clásicos en el siglo xvn.

JOHN H. TURNER

Bowdoin College.

\section{FUENTES Y RELACIONES EN LA SERRANA DE LAVERA}

Además de su fuente principal, las comedias antiguas españolas nacen de un manojo indivisible de influencias literarias; constantemente, este conjunto, de una manera o de otra, se encuentra en cada comedia y en cada poeta de la época. Lo pastoril, los libros de caballería, el romancero, el refranero, la historia, la Biblia y vidas de santos, la novela italiana, la mitología, misceláneas diversas (polianteas), la literatura toda y hasta su reflejo en la vida, el teatro anterior y el coetáneo, son las fuentes de los argumentos del "Arte nuevo".

La afirmación anterior es aplicable a la obra de Luis Vélez de Guevara, La serrana de la Vera. Aparte del fuerte influjo pastoril que lleva diluido $^{1}$, la forman un buen número de refranes - unos veinte ${ }^{2}-$, el romancero (los romances populares de serrana como leitmotiv del asunto $^{3}$, juramentos épicos del romancero carolingio, v. 2140-50), alusiones históricas de varios tipos (por una parte las Amenidades... de la Vera ... de G. Azedo ${ }^{4}$; por otra, menciones de personajes célebres como Semíramis, Evadnes, Wamba, Césàr) ${ }^{5}$, alusiones mitológicas (Palas, Fénix, etc.) y literarias (Aldonza, Beatriz, Aquiles, Fray Guarín, Olimpia, Bireno) ${ }^{6}$. Está, además, la lírica de tipo tradicional (canciones populares de serrana de tipo zejelesco, clave de la estructura musical

1. Para lo pastoril en Lope véase F. Lóry Estrada, "Fuente Onejuna" en el teatro de Lope y de Monroy, Sevilla, 1965 y "E1 drama de Fuente Orejuna en las obras de Lope y de Monroy", $A U H, 25$ (1964), 1-91.

2 En el inventario y tasación de los bicnes de Luis Vélez, hecho en Madrid el 7 de noviempre de 1626 (Pérez. Pastor, Bibliografia Madrileña, t. 3, Madrid, 1907, p. 510), se dice "un libro de Refranes de Malara y otros 24 libros..."; ver también E. Cotarelo, Luis Vélez de Guevara y sus obras, BRAE, t. 4, p. 150.

3 La serrana de la Vera, ed. R. Menéndez Pidal, Madrid, 1916, pp. 154.135; N. Alonso Cortés, Romances populares de Castilla, Valladolid, 1906, p. 70; "Romances tradicionales", $R H i, 50$ (1920), y Romancero popular de la montaña, Santander, 1935, 2 ts. De este romance viejo de serrana bandolexa conocemos más de reinte versiones.

4 Comentadas por V. Barrantrs, Narraciones extremeñas, Madrid, 1872; y Menénibz y Pelayo, Estudios sobre el teatro de Lope de Vega, t. 6, cd. A. Bonilla, Madrid, 1927.

5 Para otras citas históricas en Luis Vélez véase Firtudes vencen señales, ed. Grazia Profeti, Pisa, 1965; nota al verso 189.

6 Estos últimos personajes son del Orlando ftrioso, cap. X; y sc cncucntran en cl Quijote, en el romance de Altisidora. 